\title{
Tourists and Crocodiles in Uganda
}

\author{
Hugh B. Cott
}

Early in 1969, at the request of the Director of Uganda Nationa Parks, Dr. Cott made a third survey of the status and biology of the Nile crocodile on the Victoria Nile below Murchison Falls, continuing the field studies he made in 1967 and 1968 . This report on his 1969 work supplements that on the earlier studies (see ORYX, September, 1968) and reinforces his previous findings and recommendations. In 1969 the crocodiles again lost many eggs to predators, and the main cause was still human disturbance-by poachers and tourist launches. Once again, Dr. Cott urges that tourist launches must be kept away. The FPS is supplying a leaflet to be given to all tourists explaining why.

\section{Breeding Season}

Observations at $\mathrm{r} 20$ nests during each of the two seasons 1968 and 1969 have afforded new information on the time and duration of the crocodile breeding season on the Victoria Nile below Murchison. Precise layingdates are known for several nests in each year, and laying dates for other clutches have been estimated from measurements of embryos and from a study of embryonic growth-rate.

The following table shows the distribution of laying-dates in ten-day periods, from beginning to end of the laying season.

\begin{tabular}{lccccccccc} 
& \multicolumn{3}{c}{ December } & \multicolumn{3}{c}{ January } & \multicolumn{4}{c}{ February } \\
I969 & I & 4 & 14 & 25 & 28 & 35 & IO & 3 & - \\
I968 & - & I & II & 27 & 42 & 28 & 9 & I & I \\
Total & I & 5 & 25 & 52 & 70 & 63 & I9 & 4 & I
\end{tabular}

Laying begins about mid-December, builds up to a peak in January, when more than three-quarters of all clutches are laid: $1969-88$ (73 per cent); 1968-97 (8I per cent), followed by a steep decline into February. The incubation period ranges from about I I to 13 weeks, or longer depending upon conditions at the nest site; the normal period is about 84 days. Development is facilitated where insolation is high and humidity low, but retarded in damp surroundings.

Hatching dates are known for 69 nests:

\begin{tabular}{lcccrcccc} 
& \multicolumn{3}{c}{ March } & \multicolumn{3}{c}{ April } & \multicolumn{2}{c}{ May } \\
1969 & 2 & 8 & II & 6 & 6 & 7 & 2 & I \\
1968 & - & 3 & 12 & 8 & 3 & - & - & - \\
Total & 2 & I I & 23 & 14 & 9 & 7 & 2 & I
\end{tabular}

\section{Nesting Population}

In February, March and April 1969 the detailed survey of breeding females was repeated between the Falls and Paraa and extended from Paraa westwards to Buligi. Changes compared with the previous season were found in the occupation of nesting grounds. Several long-established grounds were entirely deserted this year, including: on the north 


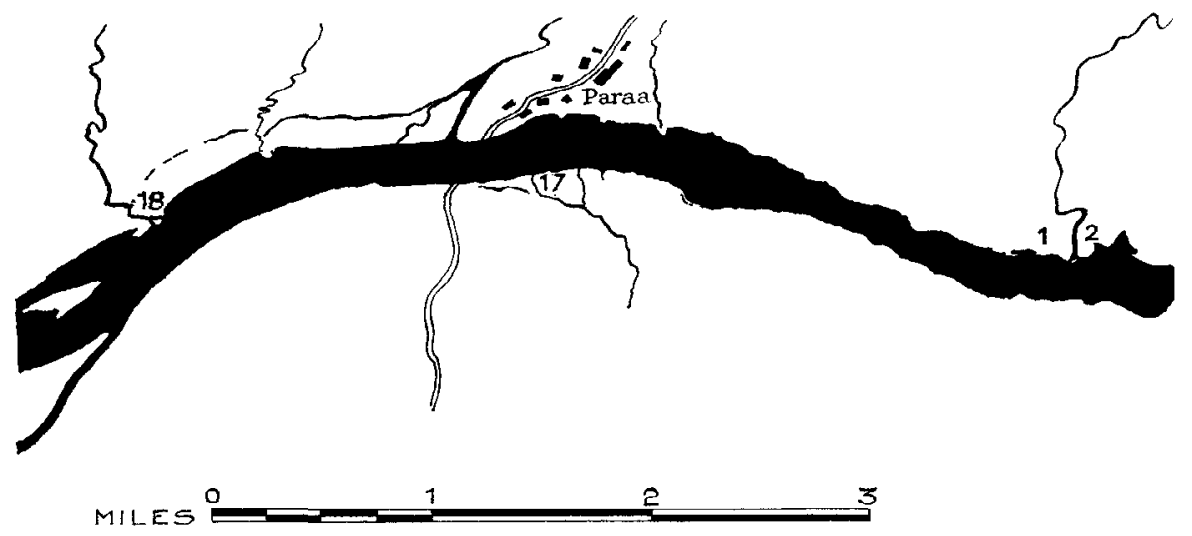

The Nile in Murchison Falls National Park. The Falls are at the far right where the river narrows to a thin line. The figures indicate nesting sites.

bank-Sand-river 3 (4), Sand-river 4 (7) and Fajao Bar (9); on the south bank-Upper Lawn (II) and Sand-river I (I5). (The figures in brackets are the map references.)

The desertion of long-established grounds, such as Fajao Bar, Upper Lawn and Sand-river $r$, was almost certainly caused by meteorological factors. The water-table had risen and sand was damp or waterlogged at egg-chamber depth. At Fajao Bar bare earth and scanty grass had been replaced by dense grass cover-including Panicum repens, which appears to require a high water-table, and Centella asiatica which is generally found in places too wet for nesting (information supplied by Dr. J.M. Lock).

The number of nests on main breeding grounds for which comparative data for the two years are available, is shown below:

\begin{tabular}{|c|c|c|c|c|}
\hline \multirow{3}{*}{$\begin{array}{c}\text { Map } \\
\text { reference } \\
\text { I \& } 2\end{array}$} & \multirow{2}{*}{$\begin{array}{l}\mathbf{N} \text { or } \mathbf{S} \text { Bank and } \\
\text { name }\end{array}$} & \multicolumn{3}{|c|}{ Number of nests } \\
\hline & & 1969 & 1968 & Change \\
\hline & N Namsika E \& W & Io & 20 & $-\mathbf{I O}$ \\
\hline 3 & N Sand-river 2 & 5 & IO & \\
\hline 4 & N Sand-river 3 & 0 & 12 & -12 \\
\hline 5 & N Bee-cater slope & 13 & I0 & +3 \\
\hline 6 & N Labyrinth & 5 & 14 & -9 \\
\hline 7 & N Sand-river 4 & 0 & 9 & -9 \\
\hline 8 & N Fajao Sands & 29 & 16 & +13 \\
\hline 9 & N Fajao Bar & 0 & 15 & -15 \\
\hline Io & N Falls Bay & 36 & 22 & +14 \\
\hline I I & S Upper Lawn & 2 & $2 I$ & - I9 \\
\hline I4 & $S$ Sand-river 4 & 13 & 8 & + \\
\hline 15 & $S$ Sand-river $\mathbf{I}$ & 0 & 19 & - I9 \\
\hline
\end{tabular}

On the twelve nesting grounds listed above, eight grounds show a loss of 98 nests, and four grounds show a gain of 35 nests. This is a drop of 36 per cent, from 176 nests in 1968 to 113 nests in 1969 . 


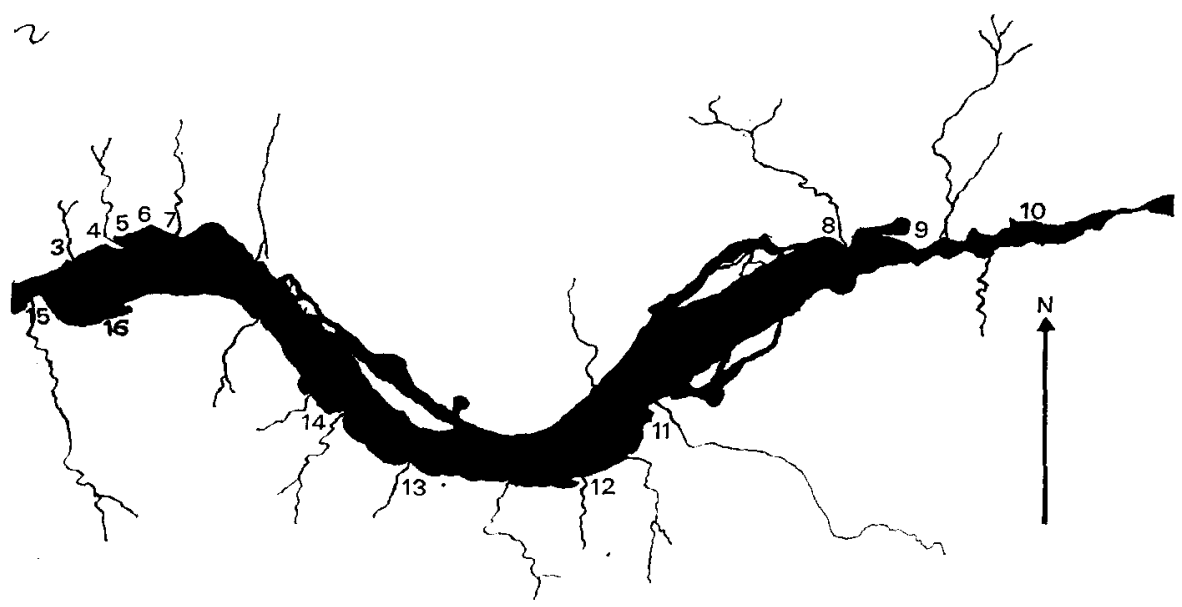

But the facts are deceptive. Four other breeding grounds, not included in the 1968 survey, have been located, namely: on the south bankFrog Bay (I6), opposite the Bee-eater slope (7 nests), and Paraa south (I7) opposite Paraa Lodge ( 7 nests); on the north bank-Sand-river (I8) about two miles west of Paraa ( 22 nests), and Buligi, about half-amile below Buligi Ranger Post (IO nests). The two north bank sites almost certainly represent newly-established nesting grounds, and may indicate a movement of crocodiles down river in search of disturbancefree terrain. The small breeding grounds on the south bank at Frog Bay and Paraa South are both secluded: if used in 1968 they were overlooked, and my attention was drawn to them by Mr. Ian Parker, who in 1969 located them from a helicopter.

A total of 176 nests was found in 1969 , including isolated nests found outside the main breeding places; this compares with I8I in I968. There is a striking disparity in the numbers found on the north bank (r39) compared with the south bank (only 37 ): i.e. almost 80 per cent of all nests in 1969 were on the Acholi side of the river.

\section{Clutch Size}

Clutch counts of 123 nests gave a mean clutch size of 55.4 , which is very close to the 1968 mean of 53.9. The following table shows the main nesting-grounds arranged in descending order of productivity:

$\begin{array}{clcc}\begin{array}{c}\text { Map } \\ \text { reference }\end{array} & \begin{array}{c}\text { N or S Bank } \\ \text { and Name }\end{array} & \begin{array}{c}\text { No. of clutches } \\ \text { counted }\end{array} & \begin{array}{c}\text { Mean } \\ \text { clutch size }\end{array} \\ \text { Io } & \text { N Falls Bay } & 31 & 57.5 \\ 8 & \text { N Fajao Sands } & 22 & 53.8 \\ \text { I8 } & \text { N Sand-river -2 } & 15 & 56.7 \\ \text { I \& } 2 & \text { N Namsika E \& } & 9 & 62.3 \\ 5 & \text { N Bee-eater slope } & 8 & 52.3 \\ \text { 17 } & \text { S Paraa South } & 6 & 53.7 \\ \text { I6 } & \text { S Frog Bay } & 5 & 51.4 \\ - & \text { Others } & 27 & 53.4\end{array}$




\section{Nest Histories}

Of the 176 nests whose history is known, 96 clutches of eggs were entirely destroyed by egg-eating enemies and 23 clutches failed to develop as a result of damp or flooding. From the remaining 57 nests at least some young were hatched from each. Comparative figures for the two seasons are shown below:

$\begin{array}{ccccc}\text { Season } & \text { Nests } & \text { Predation } & \text { Damp } & \text { Hatched } \\ 1969 & 176 & 96(54.5 \%) & 23(13.1 \%) & 57(32.4 \%) \\ 1968 & 174 & 97(55.7 \%) & 29(16.7 \%) & 48(27.6 \%) \\ \text { Total } & 350 & 193(55.1 \%) & 52(14.9 \%) & 105(30.0 \%)\end{array}$

\section{Predatory Egg-eaters}

The following table shows the predators responsible for losses in the nests that were entirely eaten-out. This includes instances of multiple attack by more than one species-here included in the score against the several species concerned. Comparable data for 1968 are included.

1969

Predator

Olive baboon

White-tailed mongoose

Serval

Spotted hyaena

Honey badger

Kite

Marabou

Palmnut vulture

Nile monitor

\section{(63 nests)}

12

3

$\frac{1}{23}$

23

I

3

2

34
1968

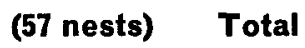

\begin{tabular}{rr}
23 & 35 \\
8 & II \\
I & I \\
I3 & 36 \\
6 & 6 \\
I & 2 \\
I & 4 \\
$\overline{I 6}$ & 2 \\
\hline
\end{tabular}

Three species stand out as the important enemies-Nile monitor and olive baboon by day, and spotted hyaena by night. Together they account for the destruction of more than 80 per cent of clutches which are lost to predators.

\section{Incidence of Predation}

The approximate date when nests were eaten-out by predators is known for 66 clutches in 1968, and for 57 clutches in 1969, and shown in this table (no records are available for December and early January):

$\begin{array}{lccccc} & \text { January } & \text { February } & \text { March } & \text { April } & \text { May } \\ \text { 1969 } & ? & 23 & 27 & 5 & 2 \\ 1968 & 9+? & 25 & 26 & 6 & - \\ \text { Total } & 9+? & 48 & 53 & \text { II } & 2\end{array}$

These records indicate that egg-eaters are active throughout the incuba-

Plate 1 opposite: IN MURCHISON FALLS NATIONAL PARK. A tourist launch disturbing the breeding crocodiles at Bee-eater slope. Hugh Cott 
$m=24$

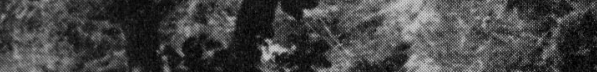

r.

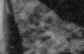

$x+3$

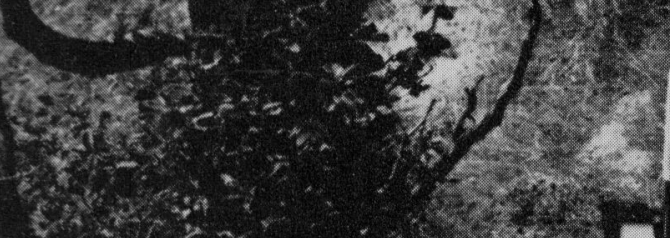

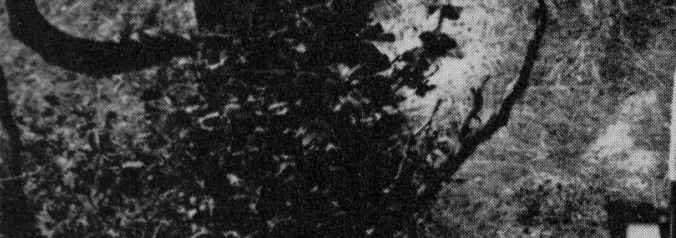

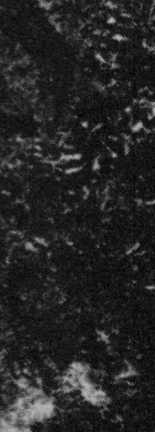

12:

s]

- $45^{2}$

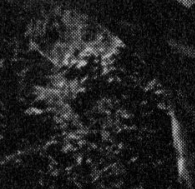

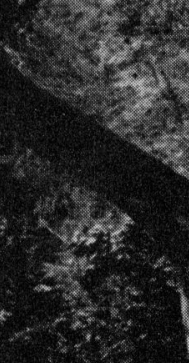

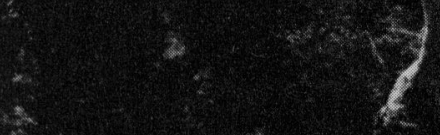

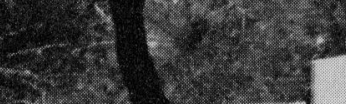

- 1.

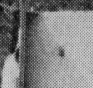

.

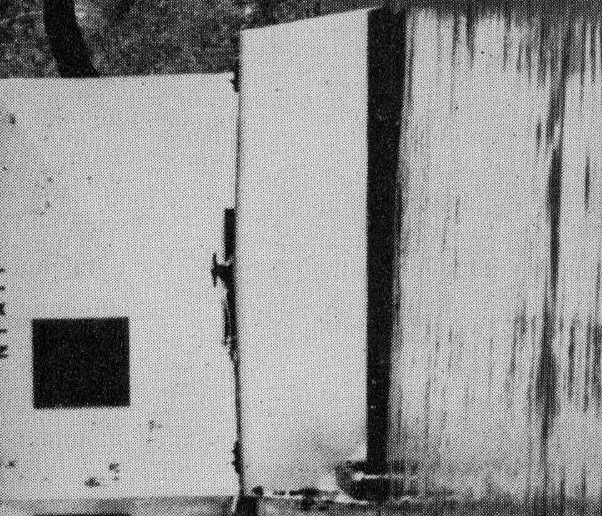

28.
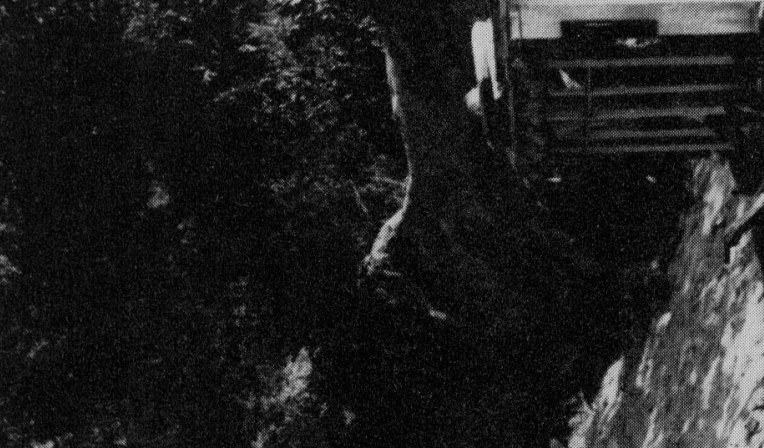

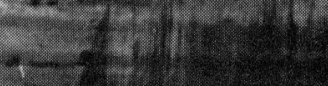

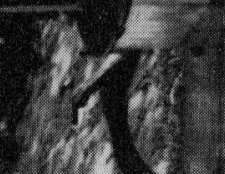

1.

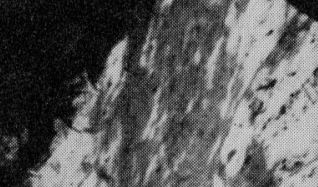

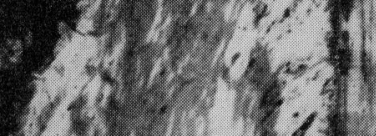

(1)

-
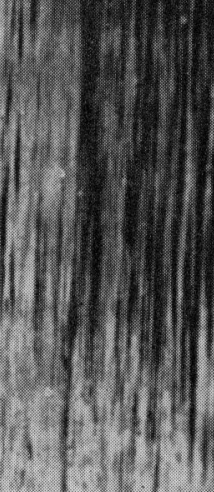

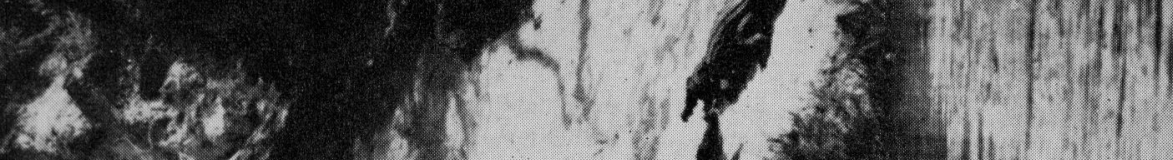

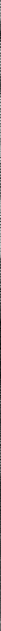




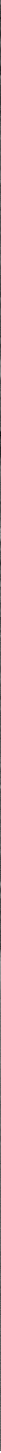

Plate 2

CONFISCATED CANOES. Aerial photograph of Buligi Ranger's post in the Murchison Falls park surrounded by dug-out canoes confiscated from poachers-all now with a hole punched in the bottom. Michael Woodford 
tion period, which for late breeders extends to early May. In the two seasons covered by the survey, nest losses were heaviest in midFebruary and again in mid and late March. Baboons, hyaenas and monitors destroy the eggs without regard to the state of embryonic development, although baboons do discriminate in favour of viable, as opposed to rotten eggs.

\section{Egg Predation and Human Disturbance}

The 1968 report stressed the role of disturbance as a factor leading to nest desertion. Predation by egg-eating enemies can only occur when a nest has been abandoned by the guardian female crocodile. The high egg mortality in the I 968 season was regarded as a secondary effect of human disturbance by poachers and launch parties, and this conclusion is borne out by the 1969 observations. In general the histories of clutches at the main grounds indicate a relation between hatching-success and seclusion on the one hand, and disturbance and clutch-loss on the other.

The fate of clutches on main breeding grounds in 1969 is shown in this table:

\section{Breeding}

ground,

No. of

bank and name

N Falls Bay

N Fajao Sands

N Sand-river 2 nests

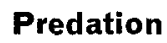

36
29
22
13
13
10
10
7
7

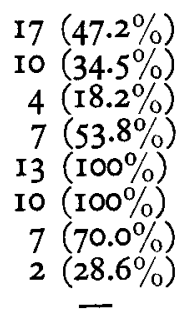

Damp

I (2.8)

Io $(34.5 \%)$

$5(22.7 \%)$

$3(23.1 \%)$

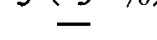

I $(10.0 \%)$

I $(14.3 \%)$
Hatched

I8 $(50.0 \%)$

$9(31.0 \%)$

$13(59.1 \%)$

$3(23.1 \%)$

$S$ Sand-river 4

N Namsika E \& W

N Buligi

S Frog Bay

S Paraa South

The four grounds with highest hatching success are all relatively free of disturbance. Falls Bay, protected by turbulence in the gorge, is inaccessible by boat. Frog Bay on the south bank, protected by shallows, is hidden behind a wall of papyrus. Paraa South, opposite the Lodge, is denied to launches because of shallow water and its central position deters poachers. Sand-river 2 appears to be a newly-established site; situated about a mile below Paraa, it is outside the tourist range.

The four grounds showing the highest predation-rate are Namsika, Bee-eater slope, and Buligi on the north bank, and Sand-river 4 on the south bank. Of these the Namsika site is a magnet to tourist launches, the mouth of this confluent being the haunt of the spectacular flock of skimmers. In 1969 all ten nests, and in 1968 all twenty nests were destroyed by predators-spotted hyaena, white-tailed mongoose, marabou stork, palmnut vulture and, especially, monitors. In the last three years the rookeries at Bee-eater slope and Sand-river 4 have been overrun by monitors, and both sites attract tourist-photographers, who are frequently able to see the lizards and baboons at work. At Sand- 
river 4 , in 1969 , all 13 nests and in 19687 out of 8 nests, were takenmostly by hyaenas and monitors. Buligi nesting site, which appears to be new, was disturbed by poachers-despite the proximity of Buligi Ranger Post. In early March several wire nooses were found on the crocodile paths leading from river to nest; seven of the ten nests were eaten-out by monitors.

\section{Maternal Care}

The I968 report stressed the important part played by the female crocodile in the successful rearing of offspring: "During the protracted cycle of egg-laying, incubation, exhumation, hatching and the first weeks of active life, eggs and young are entirely dependent upon maternal care. Disturbance of females on the nesting grounds causes high mortality both through hatching failure and predation". Recent experiments and observations on nesting behaviour and after-care by the female point once again to the crocodile's need for quiet on the nesting grounds, undisturbed by human intrusions.

\section{Care before Hatching}

When undisturbed, brooding females guard the nests day and night throughout the twelve-week incubation period. They have been observed actively defending their nests against monitors and driving off baboons. At hatching time the young respond vocally to any nearby disturbance, and their calls stimulate the mother to unearth the eggs. Such maternal help is essential for the release of the young; there is no record of hatchlings having escaped from the nest-chamber unaided. At one forsaken nest the still-buried young continued to croak for seven days; when the nest was opened up most of the young were found dead in situ, many with the head protruding from the shell. Brooding females are assiduous in carrying out this task; and will make determined efforts to remove any obstruction in their path to the nest. For example, at one nest the mother crocodile shifted a heavy iron window-frame that had been placed over the nest.

A tape recording of the calls of the young while still in the nestchamber was used to test the female crocodiles' reactions. At several nesting-grounds, both by day and night, females in the water were attracted to the sound: on two occasions (observed from hides) different females hauled out of the river and came to within a yard of the buried recorder.

\section{Care after Hatching}

Newly-hatched young are reluctant to enter water, and it is believed that they immediately seek the shelter of their mother's body. A crude model of the attendant parent-made of a crocodile's head and corrugated iron-proved to be a focal point for the young immediately on hatching. In other experiments it was found that hatchlings would hurry to a man lying near the nest. The parents lead or convey the young to a nurserysite in a creek or backwater where there is seclusion and cover. The path from a riverside nest to the nursery often leads inland and away from 
the nearest water. Without guidance at this stage, hatchlings tend to stay around the nest, where they fall a ready prey to enemies.

It is now known that a female will attend and guard her young in the nursery for a period of twelve weeks. During this time she is fiercely active in the defence of hatchlings against all comers. The gregarious hatchlings remain near their parent and frequently climb from the water to rest on her back or head. A brooding female is thus occupied with maternal duties for nearly six months in the year-over 80 days both at the nest and at the nursery.

\section{RECOMMENDATIONS}

\section{Tourism}

The facts serve to underline the vital place which parental care takes in the successful rearing of a brood. Intensive tourism, with its attendant disturbance on the breeding grounds and resulting desertion or destruction of clutches, can adversely affect recruitment of the crocodile population. Instances were again noted in 1969 of launches running alongside the more accessible basking and nesting places, as for example at Bee-eater slope (5). In certain cases every crocodile ashore was forced to leave its charge - the splash of a laggard's departure being greeted as a sporting event with a cheer from spectators.

It is again recommended that:

(a) The period December I 5 to April I 5 be declared a close season; and that during the close season the following sectors of the north bank be placed out of bounds to all launches, whether privately hired or otherwise: Namsika cliff to Sand-river 4 (7) inclusive, Fajao Sands (8) and Fajao Bar (9).

(b) Harrying or driving crocodiles from the basking places should be prohibited at all times, and instructions to that effect should be understood and observed by launch crews.

(c) Steps should be taken to acquaint tourists with the reason for imposing certain restrictions in the interests of conservation.

\section{Predation}

The havoc wrought by eaters of crocodile eggs in the area under survey is a cause for concern. Under existing conditions about 55 per cent of all clutches are totally destroyed by predators, and many other clutches partially destroyed.

It is recommended that:

(a) riverside troops of baboons be reduced by cropping;

(b) monitors resident on the crocodile rookeries be shot out;

(c) these measures should be completed by the end of November.

\section{Restocking}

The practicability of restocking the diminished crocodile population by artificial means should be examined. At present, productivity along this reach of the Victoria Nile amounts to about 10,000 eggs per annum. It is proposed that initially a pilot hatchery experiment be set up, to be followed by the establishment of a predator-proof field hatchery at 
Paraa with capacity for I000 eggs per annum. The hatchery would receive eggs from about twenty nests, hatch the young crocodiles and feed them for one year. One thousand crocodiles in their first year can be housed in an enclosure measuring $100 \times 40$ feet, and will consume on average about $50 \mathrm{lbs}$ of fish per day (information supplied by Dr H.R. Bustard). After one year the crocodiles-measuring over two feet in length and well-equipped to defend themselves from natural enemieswould be liberated at suitable sites along the river, and the hatchery would take in a fresh supply of eggs.

\section{Acknowledgments}

Sincere thanks are due to the Director, Uganda National Parks, for many facilities which made this survey possible; to the Chief Warden, Murchison Falls National Park, for his continued help and kindness; to $\mathrm{Mr}$. Chiels Margach for his interest and help with field experiments; and to Ranger Justino Ogwal who, for the third successive season, has given unfailing cooperation and practical assistance. Financial support for the survey was received from the Royal Society's IBP (International Biological Programme) grant-in-aid.

\section{Explanation for Tourists}

Following up the third recommendation in Dr Cott's report (see page $159, c)$, the FPS is supplying the park authorities with a leaflet, printed in three languages, to be presented to every visitor boarding a Nile launch, explaining why the launches must keep away from the crocodile breeding grounds and asking for their co-operation.

\section{Three Australian Films}

Two of the three Australian films bought for the FPS film library are concerned with the seals and penguins of Macquarie Island, a remote wildlife sanctuary in the Southern Ocean between Tasmania and the Antarctic. The first shows elephant seals and also fur seals, which are returning to the island after being virtually exterminated by I9th century seal hunters; the second the king, gentoo, rockhopper and royal penguins which occur in enormous numbers. The third film shows the extraordinary way in which the mound-building mallee fowl incubates its eggs, in a mound of vegetable matter, using the heat of the sun and adjusting the heap to suit the conditions. Details in the Film Library list on the inside back cover.

\section{Counting Rothschild's Mynah}

Rothschild's mynah Leucopsar rothschildi has a limited distribution on the island of Bali, in Indonesia; it is not in the Red Book but its status is unknown and difficult to discover. There are, however, considerable numbers in captivity, despite the difficulties of rearing them, and the Avicultural Society is taking an annual census of captive birds. The first census (I968) published in the Avicultural Magazine (Vol. 75, no. 3) showed $17 \mathrm{I}$ birds in 55 establishments. This is believed to be incomplete, and David Spilsbury, 5 Lambourne Avenue, Malvern Link, Worcs., would be glad to hear of any in captivity, and also from any member who has visited the bird's habitat on Bali. 